\title{
Tunable and rotatable polarization controller using photonic crystal fiber filled with
} liquid crystal

\author{
Wei, Lei; Alkeskjold, Thomas Tanggaard; Bjarklev, Anders Overgaard
}

Published in:

Applied Physics Letters

Link to article, DOI:

$10.1063 / 1.3455105$

Publication date:

2010

Document Version

Publisher's PDF, also known as Version of record

Link back to DTU Orbit

Citation (APA):

Wei, L., Alkeskjold, T. T., \& Bjarklev, A. O. (2010). Tunable and rotatable polarization controller using photonic crystal fiber filled with liquid crystal. Applied Physics Letters, 96(24), 241104. https://doi.org/10.1063/1.3455105

\section{General rights}

Copyright and moral rights for the publications made accessible in the public portal are retained by the authors and/or other copyright owners and it is a condition of accessing publications that users recognise and abide by the legal requirements associated with these rights.

- Users may download and print one copy of any publication from the public portal for the purpose of private study or research.

- You may not further distribute the material or use it for any profit-making activity or commercial gain

- You may freely distribute the URL identifying the publication in the public portal 


\title{
Tunable and rotatable polarization controller using photonic crystal fiber filled with liquid crystal
}

\author{
Lei Wei, ${ }^{1, a)}$ Thomas Tanggaard Alkeskjold, ${ }^{2}$ and Anders Bjarklev ${ }^{1}$ \\ ${ }^{1}$ Department of Photonics Engineering, DTU Fotonik, Technical University of Denmark, DK-2800 Lyngby, \\ Denmark \\ ${ }^{2}$ NKT Photonics A/S, Blokken 84, DK-3460 Birkerød, Denmark
}

(Received 18 April 2010; accepted 21 May 2010; published online 15 June 2010)

\begin{abstract}
We design and fabricate a compact tunable and rotatable polarization controller using liquid crystal photonic band gap fibers. The electrically and thermally induced phase shift in the Poincare sphere and corresponding birefringence change are measured. The direction of the electric field is managed by connecting four electrodes in different electrode configurations, and the thermal tunability is controlled by on-chip heaters. According to the results, a quarter-wave plate and a half-wave plate working in the wavelength range of $1520-1600 \mathrm{~nm}$ are experimentally demonstrated. () 2010 American Institute of Physics. [doi:10.1063/1.3455105]
\end{abstract}

Controlling the state of polarization (SOP) has become an important consideration in fiber-optic communication and optical sensing systems. Some methods for achieving polarization transformations have been developed, such as mechanical squeezing of fibers, ${ }^{1}$ rotating wave plates, ${ }^{2}$ electrooptic crystal waveguides, ${ }^{3}$ and liquid crystal (LC) retarders. ${ }^{4}$ With the recent development of photonic crystal fibers (PCFs), SOP control was proposed by using thermal tuning of the refractive index of a polymer partially infiltrated in some of the air-holes of PCF. ${ }^{5}$ Taking advantage of the large thermo-optic and electro-optic effects of LCs as well as the fast response time, ${ }^{6}$ the presence of the air-holes in PCFs makes them good hosts for LCs. ${ }^{7-9}$ In this letter, we design and fabricate a compact tunable and rotatable polarization controller based on electrically and thermally tunable LC photonic band gap (LCPBG) fiber. Under an applied electric field, the circular symmetry of a LCPBG fiber is broken due to the reorientation of $\mathrm{LC}$ molecules. The guided modes in eigenstates experience a different phase delay when they are propagating through the device. Therefore, electrically induced phase shift and corresponding birefringence change between the orthogonal polarizations in the LCPBG fiber device as a function of driving voltage are measured at different temperatures using on-chip heaters. Compared to the previously reported results, we explore an alternative mechanism on a compact platform to control the SOP by electrically and thermally changing the birefringence of the LCPBG fiber.

The cross section of the LCPBG fiber device is illustrated in the inset of Fig. 1. The all-in-fiber device assembly is mainly based on the compact on-chip design. ${ }^{10}$ The LC used in this work is MLC-6608 (Merck, Germany), which has a wavelength dependent ordinary and extraordinary refractive index of $n_{0}=1.4768$ and $n_{e}=1.5595$ at $589 \mathrm{~nm}$. The fiber is a large mode area (LMA) PCF with a solid core surrounded by five rings of air holes arranged in a triangular lattice (LMA-13, NKT Photonics A/S, Denmark). The airhole diameter, interhole distance, and outer fiber diameter are $4.3 \mu \mathrm{m}, 8.5 \mu \mathrm{m}$, and $125 \mu \mathrm{m}$, respectively. The LC MLC6608 is infiltrated for $20 \mathrm{~mm}$ of the length of the fiber by

${ }^{a)}$ Electronic mail: lewe@fotonik.dtu.dk. using capillary forces, and then mounted between two silicon v-grooves. Two single mode fibers are then placed in the grooves at each end of the LCPBG fiber to couple light in and out of the device by SU-8 fiber fixing structures which are used to obtain a high fiber coupling quality. These SU-8 structures with the thickness of $84 \mu \mathrm{m}$ also act as the spacers between the top and the bottom chip along the whole device to avoid tilting the electrodes. The electrodes and heaters are patterned by using thick photoresist coating and two-step exposure. ${ }^{11}$ The assembly is sealed with epoxy, and the top and bottom sides of the device are electrically grounded. The transmission spectra of the device for different temperatures are shown in Fig. 1. The insertion loss of the device at $1550 \mathrm{~nm}$ is around $2.8 \mathrm{~dB}$. The notch in the transmission spectrum is caused by a cladding mode crossing through the band gap, forming a so-called "avoidedcrossing" with the core mode of the band gap. ${ }^{12}$

When an electric field is applied to the LCPBG fiber, the $\mathrm{LC}$ reorients depending on the direction and strength of the applied voltage. Using four electrodes it is possible to control the direction of the electric field in the transversal direction with different electrode configurations (ECs) corresponding to three directions of the electric field (EC1: $0^{\circ}$, EC2: $45^{\circ}$, and EC3: $90^{\circ}$ ) as the dotted lines in Fig. 1, and thereby the transversal orientation of the LC molecules. The

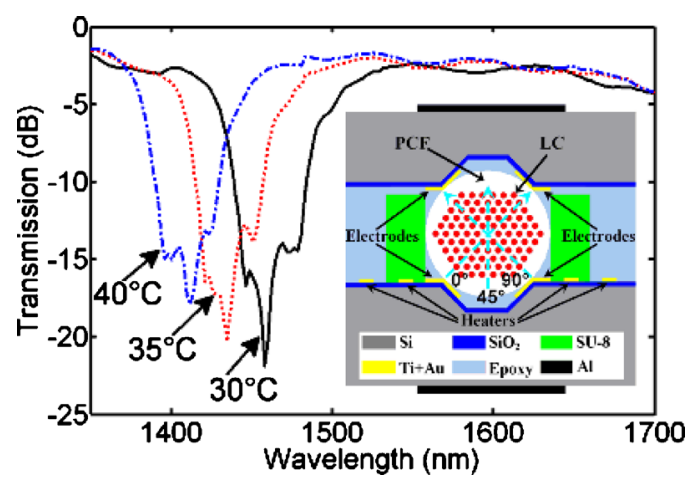

FIG. 1. (Color online) Transmission spectrum of the device by varying the temperature from 30 to $45^{\circ} \mathrm{C}$. Inset shows the cross section of the LCPBG fiber device. Dotted lines show the direction of electric field effectively applied to the LCPBG fiber. 

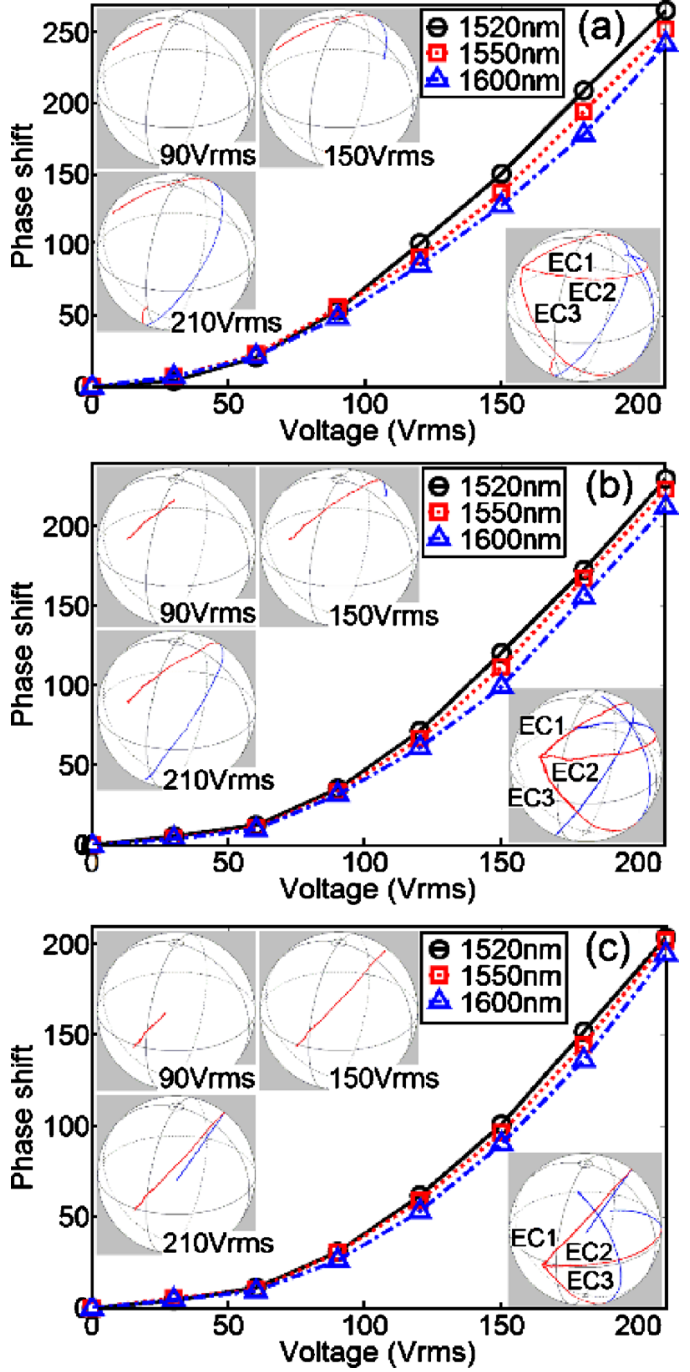

FIG. 2. (Color online) Electrically induced phase shift in EC1 as a function of driving voltage at (a) $30{ }^{\circ} \mathrm{C}$, (b) $35^{\circ} \mathrm{C}$, and (c) $40{ }^{\circ} \mathrm{C}$. Insets show the polarization states in the Poincaré sphere when a driving voltage from 90 to $210 \mathrm{~V}_{\mathrm{rms}}$ is applied.

two orthogonally polarized guiding modes in LCPBG fiber experience different refractive indices compared to the case in which the field is off and this introduces a phase shift between them. To measure the electrically induced phase shift and corresponding birefringence change, a polarized and tunable laser source operating from 1520 to $1620 \mathrm{~nm}$ is used. A polarization analyzer launches the light in the LCPBG fiber device and resolves the output light into the Stokes parameters, which are plotted on the surface of the Poincaré sphere. Actively controlled phase shift between the orthogonal polarizations in the device results in a corresponding rotation in the sphere. To achieve a tunable device with low activation loss when the electric field is applied, we consider $210 \mathrm{~V}_{\mathrm{rms}}$ as the maximum driving voltage and the maximum activation loss of $0.45 \mathrm{~dB}$ is found. The top insets of Fig. 2(a) show the phase shift in the Poincaré sphere for EC1 when a driving voltage from 90 to $210 \mathrm{~V}_{\text {rms }}$ is applied to the device at $30{ }^{\circ} \mathrm{C}$ by launching $1550 \mathrm{~nm}$ polarized laser light. The trace in the Poincaré sphere represents the continuous change of the polarization state, which starts from the near part of the sphere and ends on the opposite side of the sphere. Figure 2(a) plots the electrically induced phase shift in the device as a function of driving voltage for different

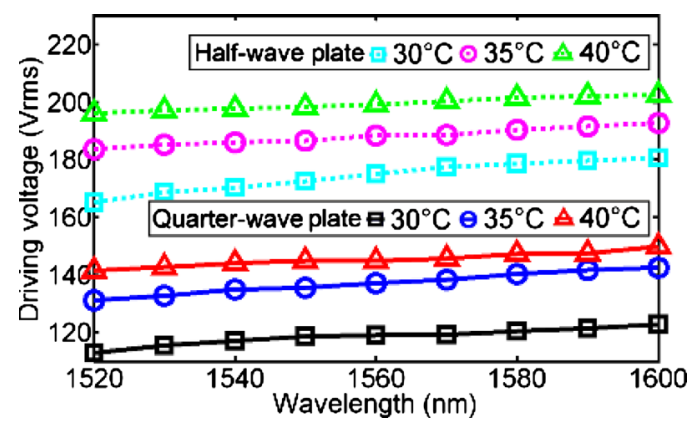

FIG. 3. (Color online) Driving voltage of EC1 as a function of wavelength for realizing quarter and half wave plates at different temperatures.

wavelengths $(\lambda)$ at $30{ }^{\circ} \mathrm{C}$. A phase shift $(\varphi)$ of $266.2^{\circ}$ for $1520 \mathrm{~nm}$ is obtained by applying $210 \mathrm{~V}_{\mathrm{rms}}$, which gives a birefringence $(\Delta \mathrm{n})$ of $5.62 \times 10^{-5}$ by the relation $\Delta \mathrm{n}$ $=\varphi \lambda / 2 \pi \mathrm{L}$, where $\mathrm{L}$ is the length of the LC filled section. Less phase shift and birefringence are observed when an input signal with a longer wavelength is launched, e.g., a phase shift of $252.6^{\circ}$ and $242.3^{\circ}$, and the corresponding change in birefringence of $5.44 \times 10^{-5}$ and $5.38 \times 10^{-5}$ are obtained for $1550 \mathrm{~nm}$ and $1600 \mathrm{~nm}$, respectively. When the direction of the electric field is effectively rotated by connecting the four electrodes in different ECs, the reorientation of LC changes subsequently. Therefore, the input light with a fixed polarization state can experience dissimilar response when it propagates through the device. The bottom inset of Fig. 2(a) shows the phase shift in the Poincaré sphere for EC1, EC2, and EC3 with the driving voltage of $210 \mathrm{~V}_{\text {rms }}$.

The same measurement has been taken for 35 and $40{ }^{\circ} \mathrm{C}$. Figures 2(b) and 2(c) plot the electrically induced phase shift as a function of voltage for different wavelengths at 35 and $40{ }^{\circ} \mathrm{C}$, and the corresponding phase shift in the Poincaré sphere with the driving voltage from 90 to $210 \mathrm{~V}_{\mathrm{rms}}$. When the temperature increases, the electrically induced phase shift decreases. This is because the birefringence of LC decreases as a function of temperature until it becomes zero at the clearing temperature.

These results demonstrate that the device can find use as a continuously tunable polarization controller but also can act as a quarter-wave plate with $90^{\circ}$ phase shift and a halfwave plate with $180^{\circ}$ phase shift. Since the electrically induced phase shift is wavelength dependent, small variations in the driving voltage are required to develop high performance polarization controllers or wave plates in the whole working wavelength range. Figure 3 plots the driving voltage as a function of wavelength for keeping the device as a quarter-wave plate and a half-wave plate at different temperatures among the wavelength range of $1520-1600 \mathrm{~nm}$. At $30{ }^{\circ} \mathrm{C}$ the maximum driving voltage variation of 10.1 and $15.5 \mathrm{~V}_{\text {rms }}$ are observed when the device performs as a quarter-wave and a half-wave plate. However, only 6.3 and $8.3 \mathrm{~V}_{\mathrm{rms}}$ variations are found to achieve a stable performance at $40{ }^{\circ} \mathrm{C}$.

In conclusion, we demonstrate a compact tunable and rotatable polarization controller using LCPBG fibers in the wavelength range of $1520-1600 \mathrm{~nm}$. This device has the potential applications as a polarimeter (a rotating wave plate and a polarizer architecture with a single detector) for 
analyzing the $\mathrm{SOP}^{13}$ or as a low-cost polarization stabilizer for optimizing the performance of polarization dependent systems or devices. ${ }^{14}$

${ }^{1}$ R. Ulrich, Appl. Phys. Lett. 35, 840 (1979).

${ }^{2}$ T. Imai, K. Nosu, and H. Yamaguchi, Electron. Lett. 21, 52 (1985).

${ }^{3}$ F. Heismann, IEEE J. Quantum Electron. 25, 1898 (1989).

${ }^{4}$ S. H. Rumbaugh, M. D. Jones, and L. W. Casperson, J. Lightwave Technol. 8, 459 (1990).

${ }^{5}$ C. Kerbage and B. J. Eggleton, Opt. Express 10, 246 (2002).

${ }^{6}$ S. T. Lagerwall, P. G. Rudqvist, and D. S. Hermann, Liquid CrystalOptical Properties and Basic Devices (Marcel Dekker, New York, 2003).

${ }^{7}$ T. T. Larsen, A. Bjarklev, D. S. Hermann, and J. Broeng, Opt. Express 11,
2589 (2003)

${ }^{8}$ L. Wei, J. Weirich, T. T. Alkeskjold, and A. Bjarklev, Opt. Lett. 34, 3818 (2009).

${ }^{9}$ L. Wei, T. T. Alkeskjold, and A. Bjarklev, Opt. Lett. 35, 1608 (2010).

${ }^{10}$ L. Wei, T. T. Alkeskjold, and A. Bjarklev, IEEE Photonics Technol. Lett. 21, 1633 (2009).

${ }^{11}$ L. Wei, E. Khomtchenko, T. T. Alkeskjold, and A. Bjarklev, Electron. Lett. 45, 326 (2009).

${ }^{12}$ D. Noordegraaf, L. Scolari, J. Lægsgaard, T. T. Alkeskjold, G. Tartarini, E. Borelli, P. Bassi, J. Li, and S.-T. Wu, Opt. Lett. 33, 986 (2008).

${ }^{13}$ R. M. A. Azzam, J. Opt. Soc. Am. A 17, 2105 (2000).

${ }^{14}$ T. Chiba, Y. Ohtera, and S. Kawakami, J. Lightwave Technol. 17, 885 (1999) 